\title{
Equity, diversity, and inclusion code of conduct for anesthesiology departments
}

\author{
John K. Peel, BHSc, MD • Gianni R. Lorello, BSc, MD, MSc (Med Ed), CIP, FRCPC (1)
}

Received: 11 September 2020/Revised: 22 October 2020/Accepted: 24 October 2020/Published online: 10 November 2020

(C) Canadian Anesthesiologists' Society 2020

To the Editor,

Equity and diversity are fundamental to the medical profession's commitment to treat everybody with dignity, respect, and value. Nevertheless, imbalances in representation, remuneration, and promotion of individuals from diverse backgrounds persist. ${ }^{1,2}$ Initiatives to support equity, diversity, and inclusion in anesthesiology are increasingly prominent, but it is imperative that departments address not only biased policies but also the culture of what is considered acceptable. ${ }^{3}$ Workplace culture encompasses the shared values, attitudes, and consequent behaviours of a group; culture defines "the rules for how [a group] will work together." ${ }^{1}$ A code of conduct explicitly directs what is the expected workplace culture; it is a tool to foster equity, diversity, and inclusion within a department. Herein, we outline the rationale for, and production of, a departmental code of conduct that is intended to cultivate a culture of equity, diversity, and inclusion within the University of

J. K. Peel, BHSc, MD

Department of Anesthesiology and Pain Medicine, The University of Toronto, Toronto, ON, Canada

G. R. Lorello, BSc, MD, MSc (Med Ed), CIP, FRCPC ( $₫)$. Department of Anesthesiology and Pain Medicine, The University of Toronto, Toronto, ON, Canada

e-mail: Gianni.Lorello@uhn.ca

University Health Network, Toronto Western Hospital Department of Anesthesia and Pain Medicine, Toronto, ON, Canada

The Wilson Centre, Toronto, ON, Canada

Women's College Research Institute, Toronto, ON, Canada
Toronto, Department of Anesthesiology and Pain Medicine.

The culture in medical specialties, including anesthesiology, is reinforced during training by observation and emulation of ones' "superiors.", Knowledge and skills aligning with a biomedical framework are usually taught in medical training. Nevertheless, specific training of professionalismincluding equity, inclusion, and respect for diversity-is inadequate. $^{4}$ By leaving the expectations for professionalism undefined, lapses in professional behaviour are often ignored. This gap in training leaves physicians without the language or skills to address unprofessional discriminatory behaviours. ${ }^{1,2,4}$ A code of conduct defines acceptable professional behaviour to dismantle discriminatory ideologies. ${ }^{2}$

Our code of conduct (Table; also available at https:// www.anesthesia.utoronto.ca/professionalismcode-conduct) intentionally is aligned with institutional standards for professional behaviour and the CanMEDS competencies. ${ }^{\mathrm{A}}$ Our incorporation of familiar terminology and concepts into a code of conduct is a technique grounded in "change management" frameworks that have been previously effective in changing physician behaviours and practices. ${ }^{5}$ By positioning an intervention in the context of existing paradigms, change is more likely to be accepted. ${ }^{5}$

\footnotetext{
A The CanMEDS framework describes the expected abilities of physicians to effectively meet the needs of their patients and is the foundation for practice standards put forward by the Royal College of Physicians and Surgeons of Canada. The CanMEDS core competencies include: medical expert, communicator, collaborator, leader, health advocate, scholar, and professional. Emphasis on these competencies in the code of conduct is made by italicizing their mention. Frank JR, Snell L, Sherbino J (editors). CanMEDS 2015 Physician Competency Framework. Ottawa: Royal College of Physicians and Surgeons of Canada; 2015.
} 
Table The University of Toronto, Department of Anesthesiology and Pain Medicine Code of Conduct*

Learn, provide care, and communicate with professionalism, honesty, compassion, and empathy while ensuring patient safety, physical, and mental well-being, regardless of individuals' socio-cultural constructs;

Apply medical expertise without distinction and with fairness to all individuals;

Advocate equitably for the needs of patients, regardless of the patients' socio-cultural constructs, and support actions and attitudes that empower socially marginalized groups;

Be considerate of the diversity of learners, staff, and patients in the learning and workplace environment and make an effort to ensure that everyone has equal work and learning opportunities, regardless of socio-cultural constructs;

Make an effort to gain expertise on how to recognize personal bias and mitigate or eliminate its impact on patient care and interpersonal relationships in general;

Refrain from originating, colluding, dismissing, or accepting any form of microaggression and/or macroaggression, but collaborate to create a cultural, physical, and psychologically safe environment for all;

As soon as appropriately feasible, communicate with your supervisor, leadership, or professional body any identified microaggressions and/or macroaggressions;

Be a leader and health advocate, recognizing, and confronting microaggressions and/or macroaggressions in the learning and work environment;

Ensure that everyone is respected and is not excluded from scholarly endeavours, either as investigators or participants, including socially marginalized groups. Wherever possible, any resulting benefits or contributions to the medical body of knowledge should take into consideration the diversity of human nature and its applicability to minorities and socially marginalized groups;

*Available from URL: https://www.anesthesia.utoronto.ca/professionalismcode-conduct

It is expected that all faculty, staff, and learners of the Department of Anesthesiology and Pain Medicine will adhere to the above standards for professionalism. This code of conduct document highlights how the CanMEDS competencies (leader, communicator, health advocate, collaborator, scholar, professional, and medical expert) relate to equity, diversity, and inclusion.

The code of conduct is one of many initiatives implemented by our department's chief diversity officer whose mandate is to ensure "that our faculty, trainees, and support staff foster a sense of professional wellbeing and quality of life by not being subjected to discrimination, intimidation, bullying, and/or harassment." 3 The code of conduct empowers individuals to support this mandate, and in doing so, revise workplace culture. Implementation of the code of conduct involved department-wide distribution and publication on the department website. The code of conduct identifies the potential for bias and offers appropriate responses to inequity. Members of the department are encouraged to evaluate their implicit biases and adjust their behaviour toward equity. For example, the specific expectation that individuals "advocate equitably for the needs of patients, regardless of socio-cultural constructs, and support actions and attitudes that empower socially-marginalized groups" addresses the potential for implicit biases and emphasizes the importance of team behaviour as culture. ${ }^{1}$ The code of conduct empowers members of the department to translate intention into action. ${ }^{1}$

A departmental code of conduct that explicitly defines a culture of equity, diversity, and inclusion is one of many necessary initiatives to update culture within the discipline of anesthesiology. We encourage adoption of this or similar codes of conduct in departments across Canada.

Acknowledgements We would like to thank Dr. Tara Der, Dr. Maha Al-Mandhari, Dr. Filipe N. Caparica Santos, and Dr. Salima Ladak for their crucial work on the Equity, Diversity, and Inclusion Committee and their work in developing the code of conduct. Thanks to Dr. Beverley Orser, Chair of the Department of Anesthesiology and Pain Medicine at the University of Toronto, for her ongoing enthusiasm to support equity, diversity, and inclusion-focused initiatives.

\section{Disclosures None.}

Funding statement None.

Editorial responsibility This submission was handled by Dr. Hilary P. Grocott, Editor-in-Chief, Canadian Journal of Anesthesia.

\section{References}

1. Shillcutt $S$, Peterson-Layne $C$. More than the money. Int Anesthesiol Clin 2018; 56: 44-58.

2. Lorello GR, Flexman AM. In reply: comment on women anesthesiologists' journeys to academic leadership. Can J Anesth 2020. DOI:https://doi.org/10.1007/s12630-020-01803-4.

3. Lorello GR. Leading progress: the role of the chief diversity officer in anesthesiology departments. Can J Anesth 2019. DOI:https:// doi.org/10.1007/s12630-019-01530-5.

4. Ginsburg S, Regehr G, Hatala R, et al. Context, conflict, and resolution: a new conceptual framework for evaluating professionalism. Acad Med 2000; 75(10 Suppl): S6-11.

5. Rampersad SE, Low DK, Martin LD. Change management in modern anesthesia practice. Int Anesthesiol Clin 2016; 54: 83-93.

Publisher's Note Springer Nature remains neutral with regard to jurisdictional claims in published maps and institutional affiliations. 